\title{
Molecular identification and characterization of Trichinella spiralis proteasome subunit beta type-7
}

\author{
Wei Yang ${ }^{1}$, Ling Ge Li, Ruo Dan Liu', Ge Ge Sun¹, Chun Ying Liu', Shuai Bing Zhang ${ }^{1}$, Peng Jiang ${ }^{1}$, Xi Zhang ${ }^{1}$, \\ Hui Jun Ren ${ }^{2}$, Zhong Quan Wang ${ }^{1 *}$ and Jing Cui ${ }^{1^{*}}$
}

\begin{abstract}
Background: Previous study showed that Trichinella spiralis proteasome subunit beta type-7 (Tspst) gene is an up-regulated gene in intestinal infective larvae (IIL) compared to muscle larvae (ML), which was screened by using suppression subtractive hybridization (SSH) and confirmed by real-time PCR. Tspst may be related to the larval invasion of intestinal epithelial cells (IECs). The aim of this study was to identify Tspst and to investigate its immune protection against intestinal T. spiralis infection.
\end{abstract}

Methods: The Tspst gene encoding a $29 \mathrm{kDa}$ protein from T. spiralis infective larvae was cloned, and recombinant Tspst protein (rTspst) was produced in an Escherichia coli expression system. The rTspst was used to immunize BALB/C mice. Anti-rTspst antibodies were used to determine the immunolocolization of Tspst in the parasite. Transcription and expression of Tspst at T. spiralis different developmental stages were observed by RT-PCR and immunofluorescence test (IFT). The in vitro or in vivo immune protection of anti-rTspst serum or rTspst against intestinal T. spiralis infection in BALB/c mice was evaluated.

Results: Anti-rTspst serum recognized the native Tspst protein with $29 \mathrm{kDa}$ in ML crude antigens. Transcription and expression of gene was observed at all T. spiralis different developmental stages (IIL, adult worms, newborn larvae, and ML). An immunolocalization analysis identified Tspst in the cuticle and internal organs of the parasite. An in vitro invasion assay showed that, when anti-rTspst serum, serum of mice infected with $T$. spiralis or normal mouse serum were added to the medium, the invasion rate of the infective larvae in an IEC monolayer was $25.2 \%, 11.4 \%$, and $79 \%$, respectively $(P<0.05)$, indicating that anti-rTspst serum partially prevented the larval invasion of IECs. After a challenge infection with $T$. spiralis muscle larvae, mice immunized with rTspst conferred a $45.7 \%$ reduction in adult worm burden in intestines.

Conclusions: In the present study, Tspst was first identified and characterized. Tspst is an invasion-related protein of $T$. spiralis IIL and could be considered as a potential vaccine candidate antigen against intestinal T. spiralis infection that merits further study.

Keywords: Trichinella spiralis, Proteasome subunit beta type-7 (Tspst), Invasion, Immune protection

\section{Background}

Trichinella spiralis is a tissue-dwelling parasitic nematode that infects humans and other mammals. Infection occurs by the consumption of raw or undercooked meat from infected animals (e.g., pigs and wild animals) [1,2]. Once ingested, muscle larvae (ML) are released from their capsules in the stomach by the digestive enzymes,

\footnotetext{
*Correspondence: wangzq@zzu.edu.cn; cuij@zzu.edu.cn

'Department of Parasitology, Medical College of Zhengzhou University, Zhengzhou 450052, P. R. China

Full list of author information is available at the end of the article
}

and activated into the intestinal infective larvae (IIL) by intestinal contents or bile after 0.9 hour post-infection (hpi), and interacted with host intestinal epithelial cells (IECs) $[3,4]$. Then, the IIL penetrate into host intestinal epithelium where they molt four times during 10-28 $\mathrm{hpi}$, and mature into adults that mate and produce the next generation of larvae $[5,6]$. So, the invasion of host IECs by the infective larvae is the first step during T. spiralis infection.

T. spiralis larvae do not possess oral appendices or a spike [7], implying that the larval invasion of IECs may 
be not simply a result of mechanical penetration but possibly mediated by excretory-secretory (ES) proteins produced by the infective larvae $[8,9]$. Moreover, after the ML were activated by bile, the activated-larvae produce or excrete a few proteins [10]. When the T. spiralis infective larvae were inoculated onto the monolayers of IECs, they invade the IECs and produced several proteins, and some of these proteins entered the IECs [11,12]. These proteins might be related with the larval invasion of IECs. However, the biological functions of the larval invasion-related proteins and the molecular mechanism of protein-IEC interaction are unknown.

Our previous studies showed that some genes of T. spiralis are differentially expressed between ML and IIL [13]. T. spiralis proteasome subunit beta type-7 (Tspst) gene was an up-regulated gene in IIL compared with that of ML, which was identified by using suppression subtractive hybridization ( $\mathrm{SSH}$ ) and then confirmed by real-time PCR [14]. The Tspst might be related with the larval invasion of IECs, but their exact biological functions are unknown. The proteasome is highly conserved during eukaryotic evolution. It is an essential component of the ATP-dependent proteolytic pathway in eukaryotic cells and is responsible for the degradation of most cellular proteins. Proteasome-mediated proteolysis refers to a selective cellular process that results in the specific degradation of either run-needed (but normal) or damaged/ misfolded proteins. Proteasome is a major mechanism by which cells regulate the concentration of particular proteins and degrade misfolded proteins [15,16]. In parasites, the proteasome is involved in the regulation of cell differentiation and replication, participation in impairment on hosts, and could be an antigen inducing immune response in host $[17,18]$. Studies on parasite proteasomes will be beneficial for better understanding of mechanisms in the invasion of host cell by parasites, also providing a new insight for prevention and control of parasitic diseases. However, to the best of our knowledge, there has been no report of the characterization and functional analysis of the Tspst.

In the present study, the Tspst gene (GenBank accession No. XM_003374391.1) encoding a $29 \mathrm{kDa}$ protein from $T$. spiralis infective larvae was cloned and identified. The expression, immunolocalization of Tspst and the immune protection of the recombinant Tspst protein (rTspst) against the intestinal T. spiralis infection in mice was also investigated.

\section{Methods}

\section{Parasites and experimental animals}

The isolate (ISS534) of T. spiralis used in this study was obtained from domestic pigs in Nanyang, Henan Province, China. The isolate was maintained by serial passage in BALB/c mice every 6-8 months. Specific pathogen-free
(SPF) female BALB/c mice aged 6 weeks were purchased from the Experimental Animal Center of Henan Province and used for the immunological studies and challenge infection. All the animal experiments reported herein were approved by The Life Science Ethics Committee of Zhengzhou University.

\section{Collection of worms and preparation of crude and ES antigens}

T. spiralis ML from infected mice at 42 days post-infection (dpi) were recovered by digestion of carcasses with $0.33 \%$ pepsin (1:31000; Sigma) and 1\% $\mathrm{HCl}$ [19]. Adult worms (AW) were isolated from the small intestines of infected mice at 3 and 7 dpi [20]. The newborn larvae (NBL) were collected from female adult worms cultured in RPMI-1640 medium containing $10 \%$ fetal bovine serum (FBS; Gibco) in $5 \% \mathrm{CO}_{2}$ at $37^{\circ} \mathrm{C}$ for $24 \mathrm{~h} \mathrm{[21].}$

The ES antigens of the ML were prepared as previously described [22]. In brief, after washing thoroughly in sterile saline, the larvae were again washed four times in serumfree RPMI-1640 medium supplemented with $100 \mathrm{U} / \mathrm{ml}$ penicillin and $100 \mathrm{U} / \mathrm{ml}$ streptomycin. The larvae were incubated in the same medium at concentration of 5000 worms $/ \mathrm{ml}$ for $18 \mathrm{~h}$ at $37^{\circ} \mathrm{C}$ in $5 \% \mathrm{CO}_{2}$. After incubation, the media contained the ES products were filtered through a $0.2 \mu \mathrm{m}$ membrane into a $50-\mathrm{ml}$ conical tube, then centrifuged at $4^{\circ} \mathrm{C}, 15,000 \times \mathrm{g}$ for $30 \mathrm{~min}$. The supernatant was dialyzed against deionized water at $4^{\circ} \mathrm{C}$ for 2 days, and then concentrated by a vacuum concentration and freeze drying (Heto Mxi-Dry-Lyo, Denmark), respectively.

The crude (somatic) antigens were prepared from $T$. spiralis ML resuspended in deionized water. The suspension was submitted to 5 cycles of freezing-thawing. The larvae were homogenized on ice in a glass tissue grinder. After this, the larval fragments were further homogenized with ultrasonication ( 99 times 3 -s cycle, $100 \mathrm{~W}, 0^{\circ} \mathrm{C}$ ). The supernatant was collected after centrifugation at $15,000 \mathrm{~g}$ for $1 \mathrm{~h}$ at $4^{\circ} \mathrm{C}$ [23].

The protein concentration of ES antigens $(1.09 \mathrm{mg} / \mathrm{ml})$ and crude antigens $(1.25 \mathrm{mg} / \mathrm{ml})$ was determined by the method described by Bradford [24].

\section{Cell culture}

In our experiments, normal mouse IECs used were obtained from fetal mouse small intestines and were susceptible to invasion by T. spiralis [25]. The IECs were cultured $\left(5 \% \mathrm{CO}_{2}, 37^{\circ} \mathrm{C}\right)$ in complete DMEM containing $4 \mathrm{mM}$ glutamine, $20 \mathrm{mM}$ Hepes, $1 \mathrm{mM}$ sodium pyruvate, $100 \mathrm{U} / \mathrm{ml}$ penicillin, $100 \mathrm{U} / \mathrm{ml}$ streptomycin, $0.1 \mathrm{U} / \mathrm{ml}$ bovine insulin (Sigma), and $10 \%$ fetal bovine serum (Gibco). The cells were used at passage 9 for the experiment. Cell monolayer was dispersed by trypsinization (0.5\% trypsin- $0.54 \mathrm{mM}$ EDTA in PBS, at $23^{\circ} \mathrm{C}$ for $\left.5 \mathrm{~min}\right)$. 


\section{Cloning, expression, and identification of Tspst}

Total RNA was extracted from the ML using Trizol (Invitrogen). The first-strand synthesis of cDNA was accomplished using AMV reverse transcriptase (Promega, USA) and oligo (dT) primers at $42^{\circ} \mathrm{C}$ for $1 \mathrm{~h}$ according to the manufacturer's instructions. The Tspst gene was amplified by PCR, and specific primers carrying Bam $\mathrm{HI}$ and HindIII restriction enzyme sites (Forward, $5^{\prime}$-CATG GATCCATGGAAGACGCTATTATATCATCTG-3'; Reverse, 5'-CATAA GCTTTCATTCCATCATTTTAGTGC TTGAAAC-3') were used. The cycling protocol was as follows: 35 cycles of $94^{\circ} \mathrm{C}$ for $45 \mathrm{~s}, 56^{\circ} \mathrm{C}$ for $45 \mathrm{~s}$ and $72^{\circ} \mathrm{C}$ for $1 \mathrm{~min}$. The purified PCR products were cloned into the expression vector pMAL-C2X (Novagen, USA) using the BamHI and HindIII sites. The recombinant plasmid was then transformed into Escherichia coli BL21 (Novagen, USA). The expression of the recombinant protein was induced with $0.5 \mathrm{mM}$ IPTG at $37^{\circ} \mathrm{C}$ for $4 \mathrm{~h}$. The pellets of the bacterial culture were harvested following the induced incubation and disrupted by sonication in $20 \mathrm{mM}$ Tris$\mathrm{HCl} / 0.2 \mathrm{mM} \mathrm{NaCl}$ buffer ( $\mathrm{pH} 7.4$ ), and the recombinant proteins was expressed in supernatant. The rTspst was purified by Amylose Pre-packed Column (NEB Ltd, China). The purified rTspst was analyzed by sodium dodecyl sulfate-polyacrylamide gel electrophoresis (SDS-PAGE) using a $5 \%$ acrylamide stacking gel and 12\% acrylamide separating gel $(83 \times 73 \times 1.0 \mathrm{~mm})$ with a Mini-PROTEAN 3 Cell electrophoresis unit (BioRad, USA) at $120 \mathrm{~V}$ for $2.5 \mathrm{~h}$ [26]. After electrophoresis, the gel was stained with $0.25 \%$ Coomassie brilliant blue R-250 for $4 \mathrm{~h}$ and then destained (10\% acetic acid and 5\% ethanol). Another gel was prepared in the same way and used for the Western blot analysis described below.

\section{Generation of anti-rTspst antibodies}

Pre-immune sera of ten female BALB/c were collected by tail bleeding 2 days prior to the first immunization. The BALB/c mice were subcutaneously immunized with $20 \mu \mathrm{g}$ of rTspst emulsified with complete Freund's adjuvant (CFA), followed by three boosts with the same amount of protein emulsified with incomplete Freund's adjuvant at 10-day intervals. Seven days after the last boost, the mice were bled, and the sera were collected.

\section{Antibody determination}

The specific IgG antibodies to rTspst in serum samples of immunized mice were determined by ELISA using corresponding rTspst protein, ES or crude antigens. The procedure of ELISA was performed as previously described [23]. Briefly, microtiter plates (Nunc) were coated with $2.5 \mu \mathrm{g} / \mathrm{ml}$ of rTspst proteins, ES or crude antigens in coating buffer overnight at $4^{\circ} \mathrm{C}$, and blocked with $200 \mu \mathrm{l}$ of PBS-0.1\% Tween 20 (PBST) containing 5\% skimmed milk. Then, $100 \mu \mathrm{l}$ of immune serum with 1:100 dilutions in PBS were added to each well and incubated at $37^{\circ} \mathrm{C}$ for $1 \mathrm{~h}$. HRP-conjugated goat anti-mouse IgG antibodies (1:5000; Southern Biotechnology, USA) were added and incubated at $37^{\circ} \mathrm{C}$ for $1 \mathrm{~h}$. The plates were developed with o-phenylenediamine dihydrochloride substrate (OPD; Sigma), and the absorbance was measured at $490 \mathrm{~nm}$.

\section{Western blot analysis}

Samples including crude antigens (15 $\mu \mathrm{g} / \mathrm{lane}), \mathrm{ES}$ antigens $(15 \mu \mathrm{g} /$ lane $)$ and the rTspst proteins ( $3 \mu \mathrm{g} /$ lane) were separated by SDS-PAGE and then transferred onto nitrocellulose membranes (Millipore, USA) using a trans-blot SD transfer cell (Bio-Rad, USA) [27]. The membranes were cut into strips, blocked with $5 \%$ skimmed milk in Tris-Buffered Saline with Tween-20 (TBST) at $37^{\circ} \mathrm{C}$ for $1 \mathrm{~h}$, and incubated at $37^{\circ} \mathrm{C}$ for $1 \mathrm{~h}$ with $1: 100$ dilutions of different mouse sera (anti-rTspst serum, serum from mice infected T. spiralis at $30 \mathrm{dpi}$ and normal mouse serum). After washing, the strips were incubated at $37^{\circ} \mathrm{C}$ for $1 \mathrm{~h}$ with HRP-conjugated goat anti-mouse IgG (1:5000 dilution; Southern Biotechnology, USA), and finally with 3, 30-diaminobenzidine tetrahydrochloride (DAB; Sigma).

\section{RT-PCR analysis of Tspst gene transcription}

To observe the transcription of the Tspst gene at different developmental stages of $T$. spiralis, total RNA was extracted from the IIL, Ad, NBL and ML of T. spiralis. RT-PCR was performed as previously described [28]. The housekeeping gene GAPDH (glyceraldehyde-3-phosphate dehydrogenase, GenBank accession No. AF452239) of Trichinella was used as a constitutively expressed standard gene, the primers were designed as follows: forward, 5' -TTAATGTCGTGGCTGTGAAT-3', and reverse, 5' -CCAGTAG AAGCAGGGATGAT-3'.

\section{Immunofluorescence test (IFT)}

IFT was used to observe the expression of Tspst gene at different developmental stages and its immunolocalization in the parasite. The intestines (at 2 hours post infection, 3 and $7 \mathrm{dpi}$ ) and skeletal muscles (at 19 and $42 \mathrm{dpi}$ ) from mice infected with $T$. spiralis were collected respectively, and were fixed in $4 \%$ paraformaldehyde and embedded in paraffin. Microtome-cut 2- $\mu$ m sections were placed on slides, deparaffinized in xylene and rehydrated. The whole parasites and tissue sections were blocked with $5 \%$ normal goat serum in PBS and then incubated in a moist chamber at $37^{\circ} \mathrm{C}$ for $1 \mathrm{~h}$ with a $1: 10$ dilution of immune sera, infection sera or normal sera. After being washed three times in PBS, the whole parasites and sections were incubated with a 1:50 dilution of FITC-labeled goat antimouse IgG (Santa Cruz, USA), washed five times in PBS, and examined under a fluorescent microscope (Olympus, Japan) [9]. 


\section{Invasion assay}

ML were activated by the mouse bile (diluted 1:20 in saline) at $37^{\circ} \mathrm{C}$ in $5 \% \mathrm{CO}_{2}$ for $2 \mathrm{~h}$ [8]. The bile was removed prior to analysis by exhaustively washing the worms in PBS supplemented with $100 \mathrm{U} / \mathrm{ml}$ penicillin and $100 \mathrm{U} / \mathrm{ml}$ streptomycin, and the larvae were incubated in PBS at $37^{\circ} \mathrm{C}$ in $5 \% \mathrm{CO}_{2}$ for additional $1 \mathrm{~h}$ [29]. When the IECs cells were grown to confluence in 6-well plates (Corning, USA), each monolayer was overlaid with approximately 150 bile-activated larvae suspended in $2 \mathrm{ml}$ of semisolid medium (serum-free DMEM containing 15 mM HEPES and $1.75 \%$ agarose) mixed with a $1: 10$ dilution of antirTspst serum, serum from mice infected with $T$. spiralis, normal mouse serum [8]. After incubation at $37^{\circ} \mathrm{C}$ for $1 \mathrm{~h}$, the partial invasion of IECs by the infective larvae was observed using inverted phase-contrast microscope (Olympus, Japan), and the number of larvae in the cell monolayer was counted [25].

\section{Immune protection against challenge infection}

To determine the immune protection of the rTspst, a total of 40 female BALB/c mice were divided into four groups (immune group, maltose-binding protein (MBP) tag control group, adjuvant control group and PBS control group) of 10 mice each. The immune groups of BALB/c mice were subcutaneously immunized with $20 \mu \mathrm{g}$ of the purified rTspst protein. The vaccines were prepared at a 1:1 ratio by mixing rTspst protein in complete Freund's adjuvant (CFA) for the first immunization or incomplete Freund's adjuvant for the subsequent immunizations (three boosts at 10 day-intervals) and administered intradermally at multiple sites of the abdomen. The control group received PBS with the corresponding adjuvant, MBP tag or PBS only. Ten days after the last immunization, all the four groups of mice were orally challenged with 300 T. spiralis muscle larvae. Ten mice from each group were euthanized 7 days after challenge and the numbers of intestinal adult worms were counted [30,31]. The intestinal protective immunity was calculated as the worm reduction rate of recovered adult worms in intestine from the immunized group versus those from the control groups [26].

\section{Statistical analysis}

All of the statistical analyses of the data were performed using SPSS for Windows, version 17.0 (SPSS Inc., Chicago, IL). The AW recovery data were expressed as the mean value \pm standard deviation, and the differences among the groups were analyzed using the one-way ANOVA method. The statistical significance was defined as $P<0.05$.

\section{Results}

Molecular cloning and expression of a cDNA encoding Tspst The full coding sequence of Tspst gene was cloned into the prokaryotic expression plasmid pMAL-C2X. After being induced with $0.5 \mathrm{mM}$ IPTG, BL21 bacteria harboring pMAL-C2X-Tspst expressed a $72 \mathrm{kDa}$ fusion protein. On SDS-PAGE analysis, the molecular size of the rTspst was consistent with the predicted combined size of the protein encoded by the cDNA clone $(29 \mathrm{kDa})$ and MBP tag from the vector (43 kDa) (Figure 1).

\section{Western blot and ELISA analysis of the recombinant Tspst protein}

Western blot analysis showed that the rTspst was recognized by an anti-rTspst serum and serum from mice infected $T$. spiralis at $30 \mathrm{dpi}$. The $29 \mathrm{kDa}$ protein components of the crude antigens of $T$. spiralis $\mathrm{ML}$ were recognized by the anti-rTspst serum (Figure 2). The results of ELISA showed that anti-rTspst serum recognized the rTspst and crude antigens, but did not recognize the ES antigens (Figure 3 ). The results indicated that Tspst is one component of the crude antigens but not from ES antigens.

\section{RT-PCR analysis}

The transcript of the Tspst gene at different developmental stages of $T$. spiralis was determined using RT-PCR and the transcript of housekeeping gene GAPDH as a control. The mRNA transcript (807 bp) for the Tspst gene was detected at all the T. spiralis developmental stages (e.g., IIL at $2 \mathrm{hpi}, \mathrm{AW}$ at $3 \mathrm{dpi}, \mathrm{NBL}$, and ML at $42 \mathrm{dpi}$ ) (Figure $4 \mathrm{~A}$ ). Furthermore, the primers for a standard gene (GAPDH)

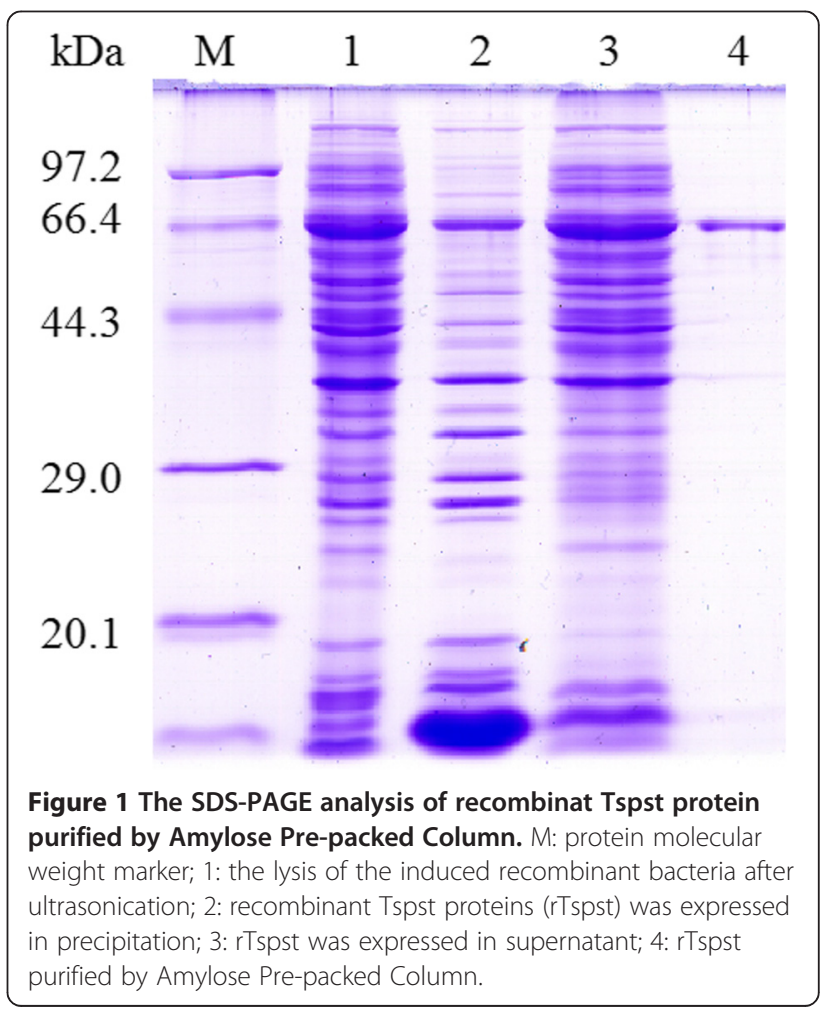



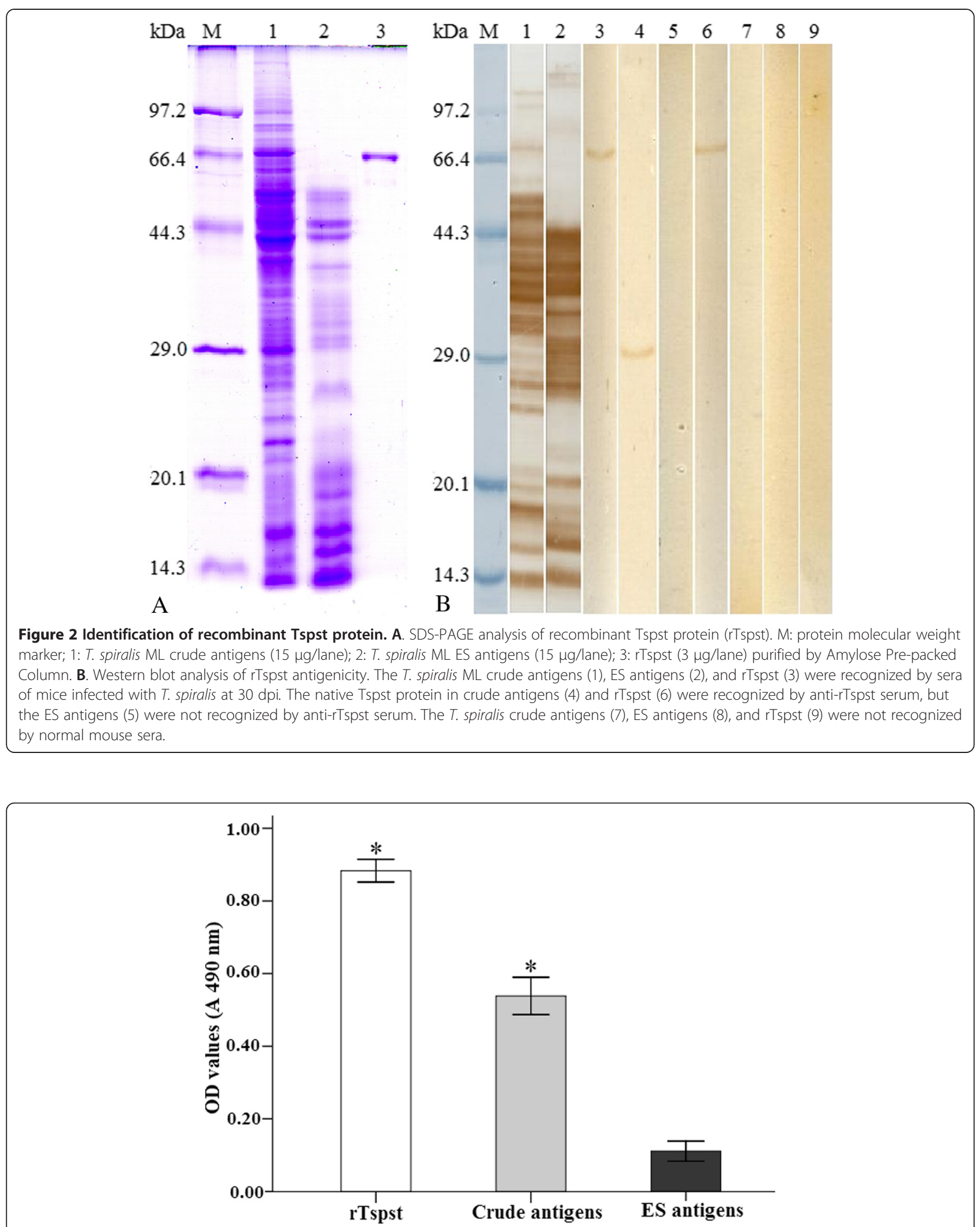

Figure 3 The specific lgG antibody levels of mice immunized with rTspst assayed by ELISA using different antigens. The optical density $(O D)$ values shown for each group are the mean \pm standard deviation (SD) of antibody levels $(n=10)$. Asterisks $\left(^{*}\right)$ indicate statistically significant differences $(P<0.01)$ in OD values of ES antigens compared to rTspst or crude antigens. 


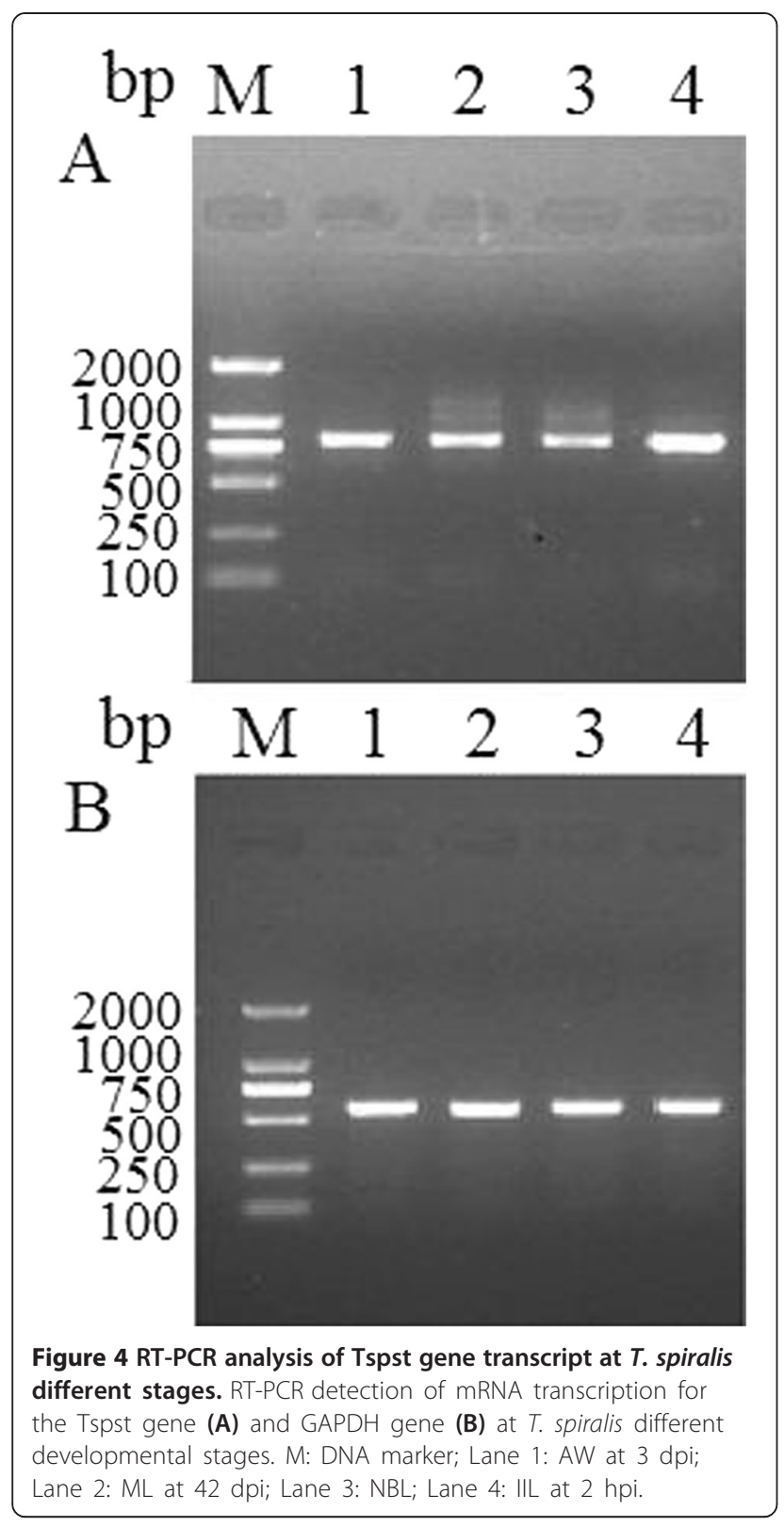

generated the expected size (570 bp) band in all of the samples (Figure 4B).

\section{Expression and immunolocalization of Tspst at different developmental stages}

The results of IFT with the whole parasite showed that the intense staining using anti-rTspst serum was found in the body of all the different developmental stages of T. spiralis (e.g., IIL at $2 \mathrm{hpi}, \mathrm{AW}$ at $3 \mathrm{dpi}$ and $7 \mathrm{dpi}$, $\mathrm{NBL}$, and ML at $42 \mathrm{dpi}$ ). When the sections of the intestines and skeletal muscle tissues of infected mice were incubated with the anti-rTspst serum, positive staining was found mainly at the cuticle and internal organs of
IIL at 2 hpi, AW at $3 \mathrm{dpi}$ and $7 \mathrm{dpi}$, pre-encapsulated larvae (PEL) at $19 \mathrm{dpi}$ and ML at $42 \mathrm{dpi}$ (Figure 5).

\section{Inhibition of larval invasion of IECs by anti-rTspst serum} When an IEC monolayer was overlaid with infective larvae suspended in a semisolid medium, the larvae invaded the monolayer and migrated through the cell monolayer. When anti-rTspst serum, serum from mice infected T. spiralis at $30 \mathrm{dpi}$ and normal mouse serum were added to the medium, the invasion rate of the infective larvae in an IEC monolayer was $25.2 \%, 11.4 \%$, and $79 \%$, respectively $\left(\chi^{2}=162.13, P<0.05\right)$ (Table 1 ). The larval invasion rate in the anti-rTspst serum and the infection serum group were significantly lower than that in the normal serum group $\left(\mathrm{X}_{1}{ }^{2}=86.87, \mathrm{X}_{2}{ }^{2}=139.67\right.$, $P<0.05)$.

\section{Immune protection of rTspst against challenge infection}

Protective immunity against intestinal $T$. spiralis infection induced by the rTspst was observed in immunized BALB/ c mice. After the challenge infection with T. spiralis ML, the mice immunized with the rTspst displayed a $45.7 \%$ reduction in their intestinal adult worms (Figure 6) compared with the groups vaccinated with PBS alone; further, the reduction of intestinal adult worms between the immunized and adjuvant or MBP tag groups was statistically significant $(\mathrm{F}=44.097, P<0.05)$.

\section{Discussion}

In the present study, the Tspst gene encoding a $29 \mathrm{kDa}$ protein from $T$. spiralis was successfully produced in an E. coli expression system, and the resulting rTspst protein and anti-rTspst serum were used to define some characteristics of the native $29 \mathrm{kDa}$ protein of T. spiralis. After being purified, such recombinant protein has a good immunogenicity in mice and can be used as an immunogen to produce antibodies [32]. Our results showed that $\mathrm{BALB} / \mathrm{c}$ mice immunized with the purified rTspst produced strong specific antibodies against the rTspst. Our Western blot analysis showed that the anti-rTspst serum obviously recognized the native Tspst protein with $29 \mathrm{kDa}$ in the crude antigens of $T$. spiralis muscle larvae. The results of ELISA also indicated that the crude antigens were reacted with anti-rTspst serum, but the ES antigens were not recognized by anti-rTspst serum. The results demonstrated that the Tspst protein might be one of component of the somatic antigens of $T$. spiralis ML.

The characteristics of Tspst were identified at the gene transcription and protein expression levels using RTPCR and IFT. As shown in Figure 4, the results of RT-PCR showed that the Tspst mRNA is transcribed during all the different developmental stages of $T$. spiralis (IIL, AW, NBL, and ML). The results of IFT revealed that the positive staining was widely found in the entire bodies 


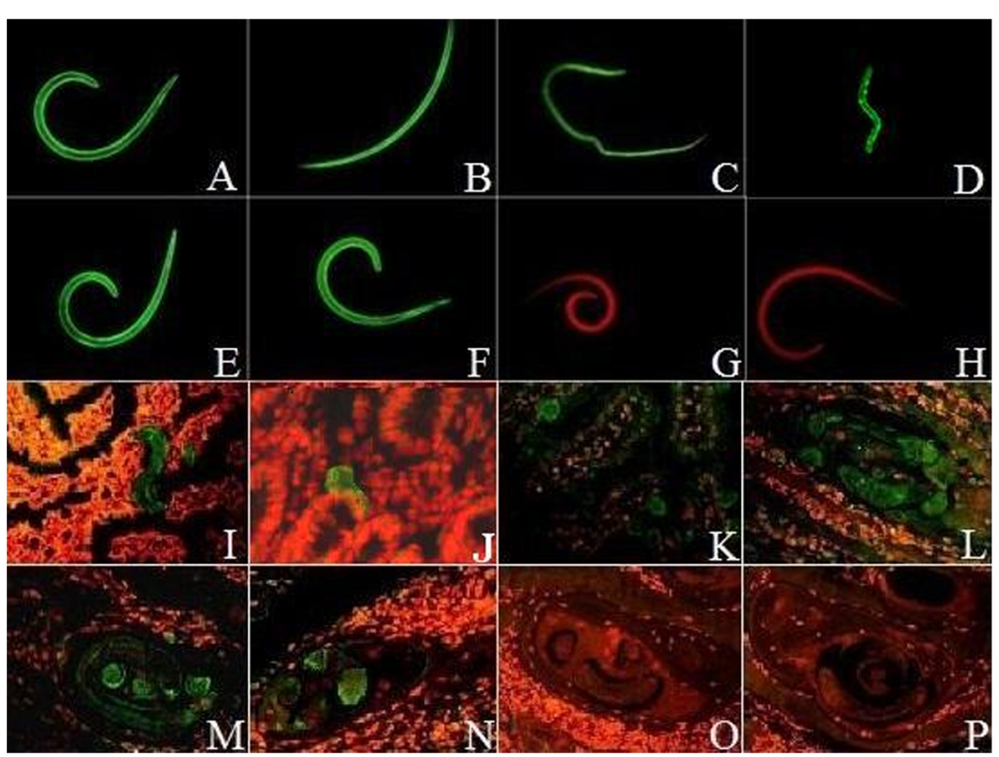

Figure $\mathbf{5}$ Expression of Tspst at different developmental stages and immunolocalization in $\boldsymbol{T}$. spiralis. A-H: The results of IFT with whole parasite of $T$. spiralis different developmental stages reacted with anti-rTspst serum. The notable immunostaning is found in the entire bodies of IIL at 2 hpi (A), AW at 3 dpi (B), AW at 7 dpi (C), NBL (D) and ML at 42 dpi (E). The ML at 42 dpi reacted with infection serum (F) as a positive control; ML at 42 dpi did not show recognition by PBS (G) and normal serum (H) as a negative control. I-P: The results of IFT with the sections of intestines and skeletal muscles of infected mice reacted with anti-rTspst serum. The immunostaning is seen at the cuticle and internal organs of IIL at 2 hpi (I), AW at 3 dpi (J), AW at 7 dpi (K), PEL at 19 dpi (L) and ML at 42 dpi (M). The ML at 42 dpi reacted with infection serum (N) as a positive control; ML at 42 dpi did not show recognition by PBS (O) and normal serum (P) as a negative control.

of the whole parasites (IIL, AW, NBL, PEL, and ML) and sections of infected intestines and muscles incubated with the anti-rTspst serum. Proteasomes are the protein complexes inside all eukaryotes, archaea and in some bacteria. In eukaryotes, they are located in the nucleus and the cytoplasm [33]. Many cellular functions and processes are conserved in proteasomes including proteolytic functions, the regulation of cell cycle, apoptosis and transcription factor, enhancement of antigen presentation. The proteasomal degradation pathway is essential for many cellular processes, including responses to oxidative stress, the regulation of gene expression, and the cell cycle. It had been predicted that the proteasome subunit beta type-7 of Caenorhabditis elegans had a function in the ATP/ubiquitin-dependent nonlysosomal protein degradation [16]. The increased expression of a $19 \mathrm{~S}$ proteasome subunit of $C$. elegans resulted

Table 1 Inhibition of anti-rTspst serum on the invasion of intestinal epithelial cells by $T$. spiralis infective larvae in vitro

\begin{tabular}{llll}
\hline Type of sera & $\begin{array}{l}\text { No. of larvae } \\
\text { added }\end{array}$ & $\begin{array}{l}\text { No. of larvae } \\
\text { invaded }\end{array}$ & $\begin{array}{l}\text { Invasion rate } \\
\text { of larvae (\%) }\end{array}$ \\
\hline Anti-rTspst serum & $156.00 \pm 7.07$ & $39.50 \pm 7.78$ & $25.24 \pm 3.84$ \\
Infection serum & $154.60 \pm 5.41$ & $17.60 \pm 3.29$ & $11.36 \pm 1.87$ \\
Normal serum & $150.80 \pm 6.30$ & $118.80 \pm 4.60$ & $78.96 \pm 5.75$ \\
\hline
\end{tabular}

in elevated somatic proteasome activity, clearance of damaged proteins and increased longevity [34]. The proteasomes have shown to play important roles in other parasites such as Entamoeba growth and encystation, Leishmania mexicana proliferation and Trypanosoma cruzi remodeling [35-37]. The previous studies showed

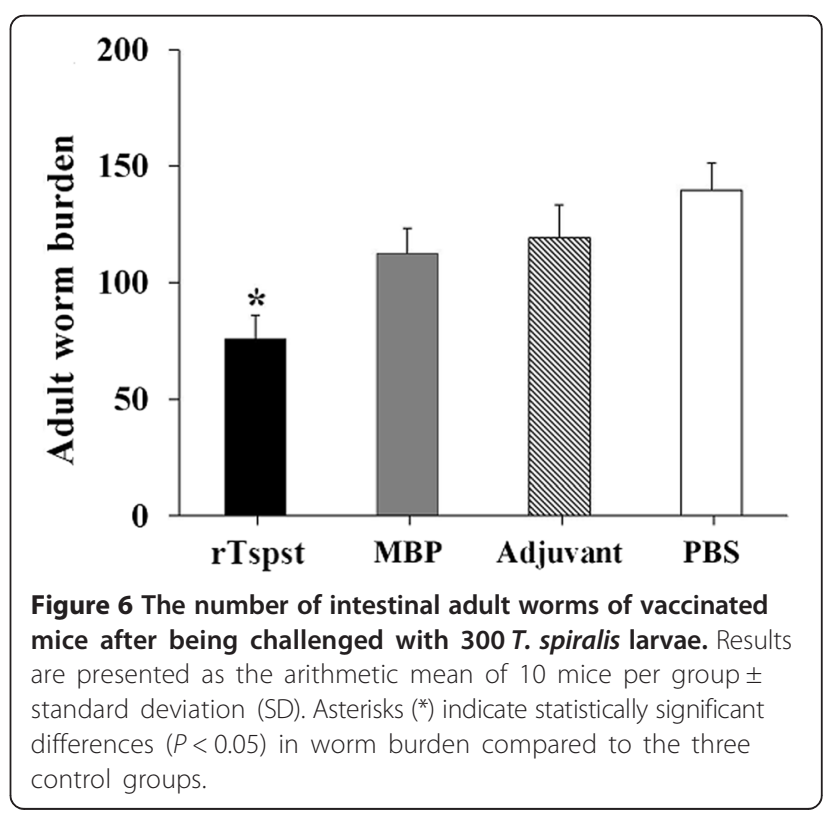


that Tspst gene was an up-regulated genes in IIL compared to ML [14]. Our results showed that Tspst gene was transcribed and expressed during all the different developmental stages of $T$. spiralis, suggesting that the Tspst is an indispensable protein and plays an important role in the larval invasion and development of $T$. spiralis larvae.

Previous studies have shown that, when suspended in a semisolid medium and inoculated onto an IEC cell monolayer cultured in vitro, $T$. spiralis infective larvae invade and migrate through the cell monolayer, leaving serpentine trails of dead and damaged cells $[13,25]$. In this study, when anti-rTspst serum was added to the medium, the invasion rate (25.2\%) of the infective larvae into the cell monolayer was significantly lower than the $79 \%$ of normal serum control groups, indicating that the anti-rTspst serum partially prevented the larval invasion of the IECs. This results demonstrated that antibodies against rTspst could reduce intestinal adult worms and protect IECs in vitro [38]. Anti-Trichinella antibodies could protect epithelia without the assistance of inflammatory cells, soluble cofactors, or mucus [39]. The mechanism of the blockage of the larval invasion of IECs by specific antibodies may be related to the formation of larval cephalic immune complexes that may physically block invasion or may interfere with sensory reception [40]. Furthermore, after the challenge infection with $T$. spiralis infective larvae, the mice immunized with the rTspst displayed a $47.5 \%$ reduction of adult worm burden in intestines. The results showed the rTspst induced a partial intestinal protective immunity in mice. Tspst might be a larval invasion-related protein, and could be considered as a potential vaccine candidate against intestinal $T$. spiralis infection.

\section{Conclusions}

The present study showed that the Tspst gene was transcribed and expressed at all the different developmental stages of $T$. spiralis. Furthermore, Tspst was located mainly at the cuticle and internal organs of the parasite. The in vitro invasion assay showed that anti-rTspst serum partially prevented the larval invasion of IECs. The rTspst induced a partial protective immunity in the immunized mice, and could be considered as a potential vaccine candidate antigen against intestinal $T$. spiralis infection. Our results suggested that Tspst is an indispensable protein and plays an important role in the larval invasion and development of $T$. spiralis larvae, but its exact biological functions are needed to be further investigated.

\section{Competing interests}

The authors declare that they have no competing interests.

\section{Authors' contributions}

ZQW and JC conceived and designed the experiments. WY, RDL, LGL, GGS,

CYL, SBZ, PJ, XZ, HJR, ZQW, and JC performed some of the experiments. WY,
ZQW, and JC drafted and revised the manuscript. All authors read and approved the final version of the manuscript.

\section{Acknowledgements}

This work was supported by the National Natural Science Foundation of China (No. 81271860, 81401682 and 30972579).

\section{Author details}

${ }^{1}$ Department of Parasitology, Medical College of Zhengzhou University, Zhengzhou 450052, P. R. China. ${ }^{2}$ Department of Laboratorial Medicine, The First Affiliated Hospital of Zhengzhou University, Zhengzhou 450052, P. R. China.

Received: 23 August 2014 Accepted: 21 December 2014

Published online: 13 January 2015

\section{References}

1. Hao Y, Zhao X, Yang J, Gu Y, Sun R, Zhu X. Monoclonal antibody targeting complement $C 9$ binding domain of Trichinella spiralis paramyosin impairs the viability of Trichinella infective larvae in the presence of complement. Parasit Vectors. 2014;7:313.

2. Murrell KD, Pozio E. Worldwide occurrence and impact of human trichinellosis, 1986-2009. Emerg Infect Dis. 2011;17(12):2194-202.

3. Zhao X, Hao Y, Yang J, Gu Y, Zhu X. Mapping of the complement C9 binding domain on Trichinella spiralis paramyosin. Parasit Vectors. 2014;7:80

4. Despommier D. Trichinella and Trichinosis. New York: Plenum Press; 1983.

5. Kang SA, Cho MK, Park MK, Kim DH, Hong YC, Lee YS, et al. Alteration of helper T-cell related cytokine production in splenocytes during Trichinella spiralis infection. Vet Parasitol. 2012;186(3-4):319-27.

6. Martinez J, Rodriguez-Caabeiro F. Relationship between heat shock protein levels and infectivity in Trichinella spiralis larvae exposed to different stressors. Parasitol Res. 2005;97(3):213-8.

7. Bruce RG. Structure of the esophagus of the infective juvenile and adult Trichinella spiralis. J Parasitol. 1970;56(3):540-9.

8. ManWarren T, Gagliardo L, Geyer J, McVay C, Pearce-Kelling S, Appleton J. Invasion of intestinal epithelia in vitro by the parasitic nematode Trichinella spiralis. Infect Immun. 1997;65(11):4806-12

9. Wang SW, Wang ZQ, Cui J. Protein change of intestinal epithelial cells induced in vitro by Trichinella spiralis infective larvae. Parasitol Res. 2011;108(3):593-9.

10. Wang L, Wang ZQ, Cui J. Protein changes in Trichinella spiralis muscle larvae in vitro induced by bovine bile. Vet Parasitol. 2013;194(2-4):164-7.

11. Wang ZQ, Wang L, Cui J. Proteomic analysis of Trichinella spiralis proteins in intestinal epithelial cells after culture with their larvae by shotgun LC-MS/MS approach. J Proteomics. 2012;75(8):2375-83.

12. Wang $L$, Wang ZQ, Cui J. Proteomic analysis of the changed proteins of Trichinella spiralis infective larvae after co-culture in vitro with intestinal epithelial cells. Vet Parasitol. 2013;194(2-4):160-3.

13. Liu RD, Wang ZQ, Wang L, Long SR, Ren HJ, Cui J. Analysis of differentially expressed genes of Trichinella spiralis larvae activated by bile and cultured with intestinal epithelial cells using real-time PCR. Parasitol Res. 2013;112(12):4113-20.

14. Ren HJ, Cui J, Yang W, Liu RD, Wang ZQ. Identification of differentially expressed genes of Trichinella spiralis larvae after exposure to host intestine milieu. PLoS One. 2013;8(6):e67570.

15. Coux O, Tanaka K, Goldberg AL. Structure and functions of the $20 \mathrm{~S}$ and $26 \mathrm{~S}$ proteasomes. Annu Rev Biochem. 1996;65:801-47.

16. Papaevgeniou N, Chondrogianni N. The ubiquitin proteasome system in Caenorhabditis elegans and its regulation. Redox Biol. 2014;2:333-47.

17. Paugam A, Creuzet C, Dupouy-Camet J, Roisin MP. Evidence for the existence of a proteasome in Toxoplasma gondii: intracellular localization and specific peptidase activities. Parasite. 2001;8(4):267-73.

18. Silva Jl, Oliveira E, Horta M, Ramalho Pinto F. Role of parasite proteasomes in the infectivity and intracellular development of Leishmania chagasi in murine macrophages. Mem Inst Oswaldo Cruz. 2000;95 suppl 2:244.

19. Li F, Cui J, Wang ZQ, Jiang P. Sensitivity and optimization of artificial digestion in the inspection of meat for Trichinella spiralis. Foodborne Pathog Dis. 2010;7(8):879-85.

20. Despommier D. A circular thermal migration device for the rapid collection of large numbers of intestinal helminths. J Parasitol. 1973;59(5):933-5. 
21. Takada N, Tada T. Collection of newborn larvae of Trichinella spiralis in vitro. Jpn J Parasitol. 1988;7:251-3.

22. Wang L, Cui J, Hu DD, Liu RD, Wang ZQ. Identification of early diagnostic antigens from major excretory-secretory proteins of Trichinella spiralis muscle larvae using immunoproteomics. Parasite Vectors. 2014;7:40.

23. Cui J, Liu RD, Wang L, Zhang $X$, Jiang $P$, Liu MY, et al. Proteomic analysis of surface proteins of Trichinella spiralis muscle larvae by two-dimensional gel electrophoresis and mass spectrometry. Parasit Vectors. 2013;6:355.

24. Bradford MM. A rapid and sensitive method for the quantitation of microgram quantities of protein utilizing the principle of protein-dye binding. Anal Biochem. 1976;72:248-54.

25. Ren HJ, Cui J, Wang ZQ, Liu RD. Normal mouse intestinal epithelial cells as a model for the in vitro invasion of Trichinella spiralis infective larvae. PLoS One. 2011;6(10):e27010.

26. Wang B, Wang ZQ, Jin J, Ren HJ, Liu LN, Cui J. Cloning, expression and characterization of a Trichinella spiralis serine protease gene encoding a 35.5 kDa protein. Exp Parasitol. 2013;134(2):148-54.

27. Cui J, Ren HJ, Liu RD, Wang L, Zhang ZF, Wang ZQ. Phage-displayed specific polypeptide antigens induce significant protective immunity against Trichinella spiralis infection in BALB/c mice. Vaccine. 2013;31(8):1171-7.

28. Zhang YL, Wang ZQ, Li LG, Cui J. Molecular characterization of Trichinella spiralis aminopeptidase and its potential as a novel vaccine candidate antigen against trichinellosis in BALB/c mice. Parasit Vectors. 2013;6:246.

29. Gagliardo LF, McVay CS, Appleton JA. Molting, ecdysis, and reproduction of Trichinella spiralis are supported in vitro by intestinal epithelial cells. Infect Immun. 2002;70(4):1853-9.

30. Martinez-Gomez F, Santiago-Rosales R, Ramon Bautista-Garfias C. Effect of Lactobacillus casei Shirota strain intraperitoneal administration in CD1 mice on the establishment of Trichinella spiralis adult worms and on IgA anti-T. spiralis production. Vet Parasitol. 2009;162(1-2):171-5.

31. Yang Y, Zhang Z, Yang J, Chen X, Cui S, Zhu X. Oral vaccination with Ts87 DNA vaccine delivered by attenuated Salmonella typhimurium elicits a protective immune response against Trichinella spiralis larval challenge. Vaccine. 2010;28(15):2735-42.

32. Harlow E, Lane D. Antibodies: A laboratory manual Cold Spring Harbor Laboratory. New York: Cold Spring Harbor; 1988.

33. Peters JM, Franke WW, Kleinschmidt JA. Distinct $19 \mathrm{~S}$ and $20 \mathrm{~S}$ subcomplexes of the $26 \mathrm{~S}$ proteasome and their distribution in the nucleus and the cytoplasm. J Biol Chem. 1994;269(10):7709-18.

34. Vilchez D, Morantte I, Liu Z, Douglas PM, Merkwirth C, Rodrigues AP, et al. RPN-6 determines $C$. elegans longevity under proteotoxic stress conditions. Nature. 2012:489(7415):263-8.

35. Makioka A, Kumagai M, Ohtomo H, Kobayashi S, Takeuchi T. Effect of proteasome inhibitors on the growth, encystation, and excystation of Entamoeba histolytica and Entamoeba invadens. Parasitol Res. 2002:88(5):454-9.

36. Robertson CD. The Leishmania mexicana proteasome. Mol Biochem Parasitol. 1999:103(1):49-60.

37. de Diego JL, Katz JM, Marshall P, Gutierrez B, Manning JE, Nussenzweig V, et al. The ubiquitin-proteasome pathway plays an essential role in proteolysis during Trypanosoma cruzi remodeling. Biochemistry. 2001;40(4):1053-62.

38. Appleton JA, Schain LR, McGregor DD. Rapid expulsion of Trichinella spiralis in suckling rats: mediation by monoclonal antibodies. Immunology. 1988;65(3):487-92.

39. McVay CS, Tsung A, Appleton J. Participation of parasite surface glycoproteins in antibody-mediated protection of epithelial cells against Trichinella spiralis. Infect Immun. 1998;66(5):1941-5.

40. McVay CS, Bracken P, Gagliardo LF, Appleton J. Antibodies to tyvelose exhibit multiple modes of interference with the epithelial niche of Trichinella spiralis. Infect Immun. 2000;68(4):1912-8.

\section{Submit your next manuscript to BioMed Central and take full advantage of:}

- Convenient online submission

- Thorough peer review

- No space constraints or color figure charges

- Immediate publication on acceptance

- Inclusion in PubMed, CAS, Scopus and Google Scholar

- Research which is freely available for redistribution

Submit your manuscript at www.biomedcentral.com/submit 